\title{
Narrative Social Work Practice for HIV/AIDS Clients
}

\author{
Yumi Oshita
}

Faculty of Health and Welfare, Prefectural University of Hiroshima, Japan

Copyright $\bigcirc 2016$ by authors, all rights reserved. Authors agree that this article remains permanently open access under the terms of the Creative Commons Attribution License 4.0 International License

\begin{abstract}
This article aims to present and discuss an innovative narrative social work theory, and to demonstrate its effectiveness through a case study of liberating a client who was dominated by HIV/AIDS discourse. The innovative construction entails four components: basic theory, clinical theory, intervention skills, and a measurement method. The selected basic theory, derived from Foucault's theory of the power of knowledge as well as Bateson's theory of difference, is aimed at theorizing a process that could help an individual to construct a new story by activating a force of differentiation in the vertical and horizontal feedback loops. Clinical theory, which provides a practical framework for problem solving, was formulated as the generation of a difference within the circular process of horizontal and vertical feedback loops. This article identifies a set of intervention skills and their effective application for generating a difference in a strategic direction. Circular questions are considered as key skills for generating a difference, while the categorization of each skill indicates a strategic application. The measurement method is theorized using modified Bales' theory to demonstrate the dynamics of the transformation process. Three-dimensional graphs are used to visualize the activation of the force of the difference.
\end{abstract}

Keywords Narrative Social Work Practice, Power of Knowledge, Differentiation, Vertical and Horizontal Feedback Loops, Intervention Skills, Circular Questions, Measurement Method

\section{Introduction}

This article presents an innovative narrative social work theory, illustrated through a concrete and successful case study of a client infected with HIV/AIDS through homosexual intercourse.

This innovative narrative social work approach comprises four components. The first component entails the basic theory for conceptualizing a process that can help a person to construct a new story by activating a force of differentiation. The theory developed here draws on Foucault's theory of the power of knowledge [1] and Bateson's theory of difference [2]. Institutionalized scientific knowledge, especially knowledge of clinical science, operates as an inhibitive force in the construction of an individual's reality. Foucault's conceptualization of this force that drives the creation of a subjective self-underpins the basic theoretical model. Foucault's conceptualization of the power of knowledge was clinically applied by Michael White and David Epston [3] as a narrative model in the field of family therapy in the late 1980s. Their narrative therapeutic model can be summarized as follows. An institutionalized discourse operates as contextual power to produce a predominant story that lets an individual accept the activities and the episodes in his/her life situation as an entire truth. Therefore, the client's problematic story is constructed by the restrictive force of the dominant story. Based on this definition of problem formation, the therapist chooses a therapeutic strategy to liberate an individual from the contextual force of the restriction of the dominant story. One skill needed to liberate a client is externalization: helping the client to objectify the restricted mechanism by which the dominant story operates. However, their definition of narrative, discourse, and story is vague, and the theoretical framework that explains the co-generational process between a specific transaction process in daily life and a narrative comprising discourse and story is not clear. In other words, the therapeutic process has not been sufficiently explained. That is, they did not succeed in theorizing a transformation theory wherein the client's beneficial story was constructed. In addition, the effectiveness of the intervention skills of externalizing cannot be explained clearly. Therefore, in this article, Bateson's theory of difference is adopted as a second relevant theory to explain this transformative process; the principle of transformation is to generate a difference in the transaction. It enables a detailed explanation of the micro-processes of a transformation, whereby individuals are shaped by the force of the dominant cultural discourse. Bateson's theory can help a person to create a force in the micro-processes that can liberate him or her from the force of a dominant story within his or her social-ecological system.

The second component is a framework for clinical theory that can explain the embedded structure and mechanism of the problem formation and resolution through amplification, using two types of feedback loops. One of these is a horizontal feedback loop that represents the transaction of speech acts between two individuals. The other is a vertical 
feedback loop that operates between embedded levels of reality construction. These embedded levels represent a modified version of the original theory of Coordinated Management of Meaning (CMM) [4]. CMM is a social constructionist theory within the social sciences that is based on Bateson's theory of difference. In micro-life processes, the mechanisms whereby an individual is liberated from the inhibitions of the dominant discourse can be generated by a differentiation method of behavior selection and meaning construction, as theorized with CMM.

The third component entails systematization of the application of intervention skills that can generate a difference resulting in the client becoming a subject who can construct a new story. The skill of externalizing described in a narrative approach has not sufficiently explained the concrete process of becoming free by the power of knowledge and the concrete element of applying the intervention skill. Therefore, in this article, the concrete element of applying specific intervention skills is targeted and its use according to the transformation procedure will be discussed in detail. It is necessary to continually apply the proposed set of intervention skills. It is also necessary to concretely visualize the process for applying intervention skills in a systematic way. To accomplish this, the social worker's intervention skills are categorized according to multiple intentions relating to the application of intervention skills. Circular questions, designed by Tomm [5-8], are primarily involved in intervention skills for generating a difference. Other intervention skills such as solution-focused questions [9] and paradoxical prescription [10] are also used systematically. Although this categorization methodology has not yet been fully theorized, progressing the categorization of strategic application of intervention skills and identifying and transforming a target element can allow the transformation process to be visualized more easily [11].

The fourth component is measurement methods devised for the process of generating a difference, clearly qualifying the effectiveness of narrative social work. In this study, an episode as the composition of the client's complaint is selected as a target to be measured as well as a target for transformation. The sequential elements of the episode are categorized according to Bales' categories [12] and visualized through the plotting of three-dimensional graphs [13-14].

The effectiveness of this narrative social work model, applying these four components of the innovation, is demonstrated through a case study of an HIV/AIDS client who initially refused his medication despite his acute physical condition. He subsequently underwent a radical attitudinal reversal that saved his life [15].

\section{Materials and Methods}

\subsection{Basic Theory}

This section discusses the basic theory applied to show the principle of the client's problem construction and solution building. A client's problem is always influenced by what Foucault [1] conceptualized as the power of knowledge. This power excludes the difference to constitute reality construction in micro-life processes. Problem resolution is then generated by activating a force of the difference, as conceptualized by Bateson [2].

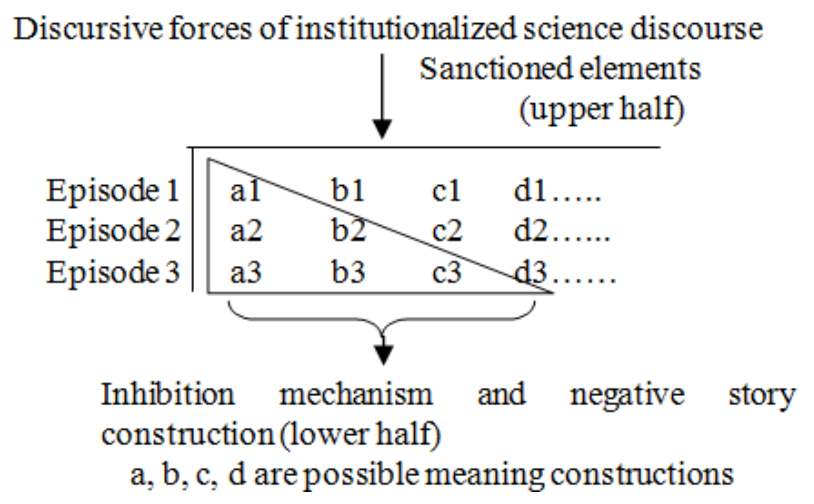

Figure 1. Structure and dynamics for eliciting a problematic episode

Figure 1 depicts the inhibition mechanism within the institutionalized science discourse that inhibits a person's micro-life processes. Episodes 1, 2, and 3 in Figure 1 indicate the client's problematic episodes involving other individuals. The signs $\mathrm{a} 1-\mathrm{d} 1, \mathrm{a} 2-\mathrm{d} 2$, and $\mathrm{a} 3-\mathrm{d} 3$ indicate possible meaning constructions of each episode. Episode 2 is constructed contextually from Episode 1, and Episode 3 is constructed contextually from Episodes 1 and 2. For example, in Figure 1, the discursive force of the institutionalized science discourse operates to elicit the meaning construction of a1 in Episode 1. Next, a2, the meaning construction of Episode 2, emerges in the context of a1 of Episode 1. Moreover, a2 of Episode 2 is connected to b2 by the subject's arbitrary selection. This formation between $\mathrm{a} 2$ and $\mathrm{b} 2$ has the power to function to inhibit the elements used to construct the meaning of the episode. Further, Episode 3 is constructed contextually from Episodes 1 and 2, and c 3 is arbitrarily connected to the meanings of a3 and b3. A client's negative story is constructed through this process of eliciting meaning constructions, namely, a1, a2, $\mathrm{b} 2, \mathrm{a} 3, \mathrm{~b} 3$, and $\mathrm{c} 3$. When this recursive force operates strongly, the person cannot become a subject capable of constructing beneficial personal stories.

To reduce this force and generate a new story, the activation of a force of differentiation is needed. As shown in Figure 1, this process is also a potentially creative process relating to the sanctioned elements during the client's construction of a negative story. For example, in Figure 1, when the client chooses al as the meaning construction of Episode 1, b1, c1, and $\mathrm{d} 1$ are sanctioned as potential elements of meaning construction.

If one of the sanctioned elements (b1, c1, and d1) of Episode 1 operates as a context for reconstructing the meaning of Episode 1, then Episode 1 will be reconstructed.

Then, if b1 of Episode 1 operates as a context to construct 
the meaning of Episode 2, $\mathrm{c} 2$ is elicited and $\mathrm{d} 2$ is connected to 2 . That is, the meaning of Episode 2 can be reconstructed by different elements than before. The composition of Episode 3 is also transformed. The client is then able to construct a new personal story and emerge from the deviance amplifying feedback loop.

One of the general complaints of patients with HIV/AIDS relates to their fear of social stigma. This is widely thought to be the reason why patients with HIV/AIDS avoid seeking proper medical treatment as well as other relevant social services [16]. As Figure 1 shows, this dominant HIV/AIDS discourse operates as a force to elicit the stigmatized episodes. Therefore, the potential elements of the stigmatized episodes will be reflected to reconstruct the stigmatized episodes as beneficial episodes.

\subsection{Clinical Theory of Transformation}

\subsubsection{Two Types of Feedback Loops}

This section describes the framework for generating a difference in the dynamic relationship that exists between two feedback loops. These vertical and horizontal feedback loops are shown in Figure 2.

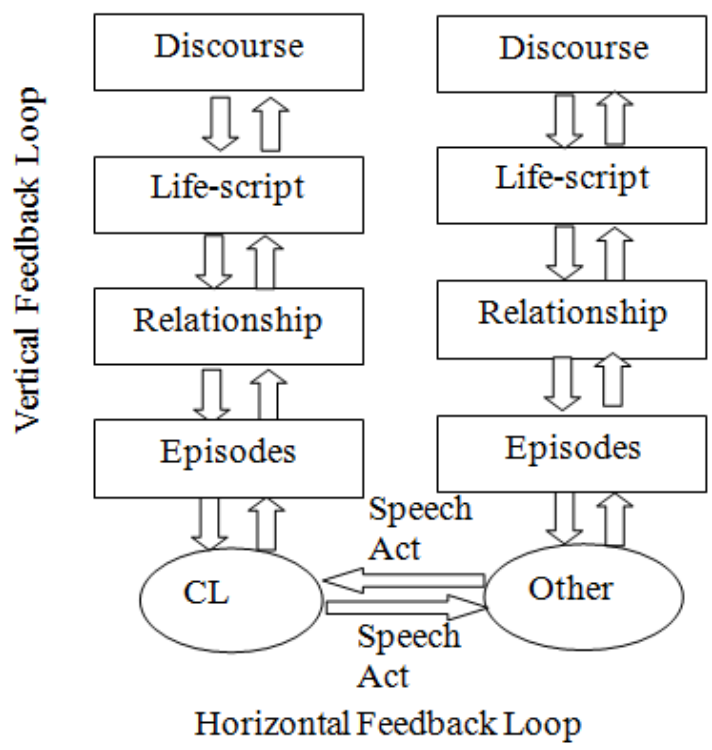

Figure 2. Vertical and horizontal feedback loops

The vertical feedback loop can be explained in terms of downward and upward forces that operate between each of the embedded levels of meaning construction. The upper levels are more abstract than the lower levels. This structure is based on a modification of CMM theory. The levels are flexible and not fixed, and each can operate as a context for constructing reality at other levels.

The downward forces are forces in which the meaning construction at upper levels of the vertical feedback loop operates as a context of the lower levels of meaning construction, the individual's life-script, and other lower levels. If this force is inhibitive, the meaning construction of the lower levels will be constructed in an inhibitive way. The downward force in the vertical feedback loop also functions as an inhibitive force limiting solution activities within the horizontal feedback loop.

The horizontal feedback loop comprises a transaction between two persons. Limited solution activities will evidently constitute an upward pre-figurative force that will inhibit the force of the differentiation in the vertical feedback loop. The activation of multiple solution activities within the horizontal feedback loop operates to activate a force of differentiation between the embedded levels of meaning construction as an upward force in the vertical feedback loop.

\subsubsection{Downward Mobility and Problem Formation}

Downward force is a mobility to construct meaning in the lower levels in the context of meaning construction in the upper levels. The framework shown in Figure 2 can be used as a map to analyze the client's complaint. For example, the client in the following case study stated, "I have no wish to live with HIV." The construction of this complaint can be explained by both downward and upward mobility. In this complaint, downward mobility from the HIV/AIDS discourse level operates strongly.

HIV infects a person primarily through sexual intercourse (the level of Discourse). When the downward mobility of a force results in its operation at lower levels, clients may construct themselves as unacceptable persons, or as persons with no life value (Life-script). This meaning of the life-script evidences downward mobility, and operates at the level of relationships with others. The client may use an inhibited definition of his or her relationship with others in terms of the self as a person who infects the other and the other as an infected person (Relationship). This definition of the relationship exhibits downward mobility, operating at the episode level. The client may construct the meaning of an episode as the refusal of another person (Episode). These embedded meaning constructions operate in the horizontal feedback loop as a pre-figurative force that reduces the choice of multiple resolution behaviors. The client's message is conveyed to the other, and the other responds to the client. The meaning of the other's message is inhibited in its construction in the vertical feedback loop, in which downward force operates strongly. That is, the other's message does not function as a differentiation force in the client's vertical feedback loop. In this mechanism with two feedback loops, the client maintains his or her construction of the suffering story as a complaint.

\subsubsection{Upward Mobility and Resolution Building}

Upward force is a mobility to construct the meaning of the upper levels in the context of the meaning of the lower levels. Figure 3 indicates the sequential elements within the horizontal feedback loop.

The other person $(\mathrm{O})$ sends a message (s1) to the client $(\mathrm{C})$. $\mathrm{C}$ constructs a meaning for $\mathrm{s} 1$ in $\mathrm{m} 1$, based on O's previous meaning construction rules. For example, "The other person's message means discouragement to me" (m1). 
Other $(\mathrm{O})$

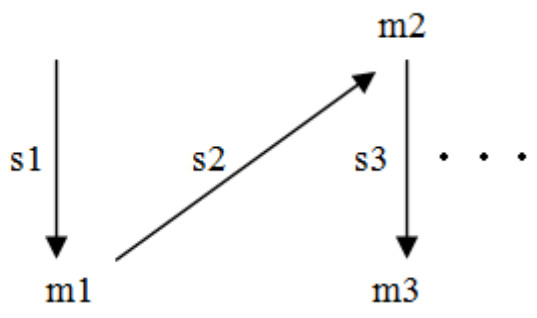

Client (C)

Figure 3. Targets of elements for change

$\mathrm{C}$ sends a message (s2) to $\mathrm{O}$ in the context of $\mathrm{m} 1$. $\mathrm{O}$ then constructs the meaning of $\mathrm{s} 2$ in $\mathrm{m} 2$ based on his or her meaning construction rules. $\mathrm{O}$ then responds to $\mathrm{C}$ with a message (s3) in the context of $\mathrm{m} 2$. Consequently, $\mathrm{C}$ then constructs the meaning of $\mathrm{s} 3$ in the context of $\mathrm{ml}$. This process continues. In the problematic episode, if $\mathrm{C}$ could construct a different meaning of $\mathrm{s} 1 \mathrm{in} \mathrm{m} 1, \mathrm{C}$ could send a differentiated message (s2) to $\mathrm{O}$. $\mathrm{O}$ receives this message and responds with a differentiated message of $\mathrm{s} 3$ to $\mathrm{C}$.

In this process, $\mathrm{C}$ could construct a different meaning of the sequence at the episode level. That is, the generation of a differentiated element in the horizontal feedback loop can generate upward mobility in the vertical feedback loop. This differentiated meaning at the episode level becomes the context for constructing a new relational meaning at the relationship level. In addition, $\mathrm{C}$ could reconstruct his/her life-script based on the differentiated meaning of the relationship.

\subsubsection{Transformation Procedure}

To activate the upward force in the vertical feedback loop, a difference needs to be generated during the transaction based on a precise transformational procedure in the horizontal feedback loop. First, the client is encouraged to narrate their complaint and describe the problematic episodes in which the complaint features. Second, the client must assume the position of problem solver for one of the episodes to construct a new story. Third, based on the social worker's circular questions, one of the elements of an episode described by the client is selected. Fourth, the social worker encourages the client to reflect on one of the elements of the sequence (e.g., m1, or s2 in Figure 3) to generate a difference using circular questions. The differentiated elements in a sequence in the vertical feedback loop can be utilized to activate a force of differentiation in the horizontal feedback loop. Fifth, the differentiated elements are therefore needed to practice in the client's life situation. A concrete practice plan is needed to generate a differentiation force in the horizontal feedback loop. Sixth, the client practices this in his/her life situation. For the last step, this implementation should be reflected again to activate upward forces in the vertical feedback loop as well as right and left forward forces in the horizontal feedback loop. When the differentiation force activates both of these loops, the client's complaint will finally be resolved.

\subsection{Intervention Skills}

\subsubsection{Theorization of the application of intervention skills}

During the therapeutic process, the social worker needs to effectively and visibly apply his or her intervention skills with a constant strategic orientation. The methodology for applying these intervention skills to satisfy these pre-conditions is theorized. Although the social worker's questioning message is usually considered to have a strong intention to intervene, in fact, the social worker's questioning message contains other potential tactical intentions that are conveyed to the client. The social worker's strong intention in a questioning message is defined as the main purpose. Simultaneously, the social worker's other potential intentions in a questioning message are defined as secondary purposes. One of the secondary purposes in sending an initial questioning message would become the main purpose in a subsequent questioning message conveyed during a well-planned interview. The representation of the purposes of a questioning message can be envisaged as being the result of the contingent and strategically oriented application of interviewing skills. The provision of a sound rationale for selecting intervention skills can help to demonstrate the effectiveness of the application of those intervention skills. Even if the social worker has already formulated a plan for the choice of their next questioning message, this plan may need to be modified in light of the client's response.

\subsubsection{Intervention Skills for Differentiation}

Table 1 depicts the core intervention skills comprising three different types of questions. These should be applied systematically. One type is the circular questions developed by Tomm [5-8]. In this article, circular questions are used to generate a difference in the most concrete level of speech acts in the embedded levels of the vertical feedback loop and in the horizontal feedback loop. The second type comprises solution-building questioning techniques, and the last comprises paradoxical techniques. The latter two types of questions are mainly used to generate a difference in the level of episodes in the vertical feedback loop. To formulate an effective application of the intervention skill, co-evolution of the activation of a force of differentiation between the speech act and episode levels is necessary. The sophisticated applications of three types of questions are necessary to thoroughly discuss the concrete case study. Therefore, the abbreviations in the last column of the table are used to represent and discuss the effective application of the social worker's interviewing skills to activate a force of differentiation.

\subsubsection{Categorization of Applied Intervention Skills}

A questioning message that has clear transformational intentions can be categorized as shown in Table 1. The multiple intentions entailed in one questioning message are divided into a main purpose and secondary purposes. Each transformational intention is categorized. 
Table 1. Categories of intervention techniques [14]

\begin{tabular}{|c|c|c|c|}
\hline \multicolumn{3}{|c|}{ Categories of techniques } & Abbreviation \\
\hline \multicolumn{3}{|l|}{ I Circular Questions } & CQ \\
\hline \multicolumn{3}{|l|}{ 1. Difference Questions } & DifQ \\
\hline \multirow{6}{*}{ 1) Category Differences } & \multicolumn{2}{|c|}{ a) between persons } & $\mathrm{CDa}$ \\
\hline & \multicolumn{2}{|c|}{ b) between relationships } & $\mathrm{CDb}$ \\
\hline & \multicolumn{2}{|c|}{ c) between perception/ideas/beliefs } & $\mathrm{CDc}$ \\
\hline & \multicolumn{2}{|c|}{ d) between actions/ events } & CDd \\
\hline & \multicolumn{2}{|c|}{ e) category difference in past } & $\mathrm{CDe}$ \\
\hline & \multicolumn{2}{|c|}{ f) category difference in future } & $\mathrm{CDf}$ \\
\hline \multirow{5}{*}{ 2) Temporal Differences } & \multicolumn{2}{|c|}{ a) between past and past } & $\mathrm{TDa}$ \\
\hline & \multicolumn{2}{|c|}{ b) between past and present } & $\mathrm{TDb}$ \\
\hline & \multicolumn{2}{|c|}{ c) between past and future } & TDc \\
\hline & \multicolumn{2}{|c|}{ d) between present and future } & TDd \\
\hline & \multicolumn{2}{|c|}{ e) between future and future } & TDe \\
\hline \multirow{2}{*}{ 3) Ordering a Series of Differences } & \multicolumn{2}{|c|}{ a) distinction made by one person } & OSDa \\
\hline & \multicolumn{2}{|c|}{ b) distinction made by several people } & $\mathrm{OSDb}$ \\
\hline \multicolumn{3}{|l|}{ 2. Contextual Questions } & ConQ \\
\hline \multirow{8}{*}{ 1) Categorical Contexts } & \multirow{2}{*}{ a) } & -1 meaning to action & CCa1 \\
\hline & & -2 action to meaning & $\mathrm{CCa} 2$ \\
\hline & \multirow{6}{*}{ b) } & -1 content/ speech act & $\mathrm{CCb} 1$ \\
\hline & & -2 speech act/ episode & $\mathrm{CCb} 2$ \\
\hline & & -3 episode/ relationship & $\mathrm{CCb} 3$ \\
\hline & & -4 relationship/ life script or family myth & $\mathrm{CCb} 4$ \\
\hline & & -5 family myth/ cultural pattern & $\mathrm{CCb} 5$ \\
\hline & & -6 mixed & $\mathrm{CCb} 6$ \\
\hline \multirow{3}{*}{ 2) Temporal Contexts } & \multicolumn{2}{|c|}{ a) behavioral effects in a dyadic field } & $\mathrm{TCa}$ \\
\hline & \multicolumn{2}{|c|}{ b) behavioral effects in a triadic field } & $\mathrm{TCb}$ \\
\hline & \multicolumn{2}{|c|}{ c) behavioral effects in larger fields } & $\mathrm{TCc}$ \\
\hline \multicolumn{3}{|c|}{ II Solution-building Questioning Techniques } & SBQT \\
\hline \multicolumn{3}{|l|}{ Exploring the exception } & $\mathrm{EE}$ \\
\hline Miracle question & & & MQ \\
\hline Scaling question & & & SQ \\
\hline Getting by question & & & GQ \\
\hline III Paradoxical techniques & & & PT \\
\hline Positive reframing & & & PR \\
\hline Paradoxical prescription & & & PP \\
\hline
\end{tabular}

\subsection{Measurement Methods}

\subsubsection{Measurement of a Transformation Process}

The measurement method applied in this study presents an activation of the differentiation forces in the target sequence, comparing pre- and post-intervention.

The object of the transformation in this study is a speech act (utterance) and a meaning construction that are basic, minimum components of a human transaction. Bales' interaction process analysis theory [12] is modified and applied to categorize the elements of the sequence. Bales' theory of qualitative measurement is a traditional qualitative measurement method for behaviors during the problem-solving process in a small group, rather than a therapeutic process. In addition, the list of categories is generally applied for measurement of behaviors. In this study, Bales' categories are used for both speech acts and meaning construction elements during the therapeutic 
process. The categorization of these elements allows us to visualize the transformational dynamism of the sequence in our unique three-dimensional graph. This visualization using three-dimensional graphs was programmed with the measurement method of intervention effectiveness (MMIE).

\subsubsection{Data for Measurement}

The speech acts and meaning constructions of the target sequence comprising the client's complaint and the transformed elements of the target sequence are used as variables to measure the effectiveness of the intervention to generate a differentiation force. The speech acts and meaning constructions are delineated as: a simple description of behavior (S) and a meaning construction of the described behavior or event (m).

\subsubsection{Theorization Measurement Using Bales' Categories}

Each speech act and meaning construction in the transaction between the client and the other, which consists of the target sequence, was categorized using Bales' categories (Table 2). Each category was chosen in the context of these elements by more than two professionals who understood the methodology of this measurement.

Table 2. System of categories used for observation [12]

\begin{tabular}{|c|c|}
\hline Area & Abbreviation \\
\hline \multicolumn{2}{|c|}{ A. Social- emotional area: Positive reaction } \\
\hline $\begin{array}{l}\text { 1. Shows solidarity, raises other's status, gives } \\
\text { help, rewards. }\end{array}$ & A1 \\
\hline $\begin{array}{l}\text { 2. Shows tension release, jokes, laughs, shows } \\
\text { satisfaction. }\end{array}$ & $\mathrm{A} 2$ \\
\hline $\begin{array}{l}\text { 3. Agrees, shows passive acceptance, understands, } \\
\text { concurs, complies. }\end{array}$ & A3 \\
\hline \multicolumn{2}{|c|}{ B. Task area: Neutral attempted answers } \\
\hline $\begin{array}{l}\text { 4. Gives suggestion, direction, implying autonomy } \\
\text { for others. }\end{array}$ & B4 \\
\hline $\begin{array}{l}\text { 5. Gives opinion, evaluation, analysis, expresses } \\
\text { feelings, wish. }\end{array}$ & B5 \\
\hline $\begin{array}{l}\text { 6. Gives orientation, information, repeats, } \\
\text { clarifies, confirms. }\end{array}$ & B6 \\
\hline \multicolumn{2}{|l|}{ C. Task area: Neutral questions } \\
\hline $\begin{array}{l}\text { 7. Asks for orientation, information, repetition, } \\
\text { confirmation. }\end{array}$ & $\mathrm{C} 7$ \\
\hline $\begin{array}{l}\text { 8. Asks for opinion, evaluation, analysis, } \\
\text { expression of feeling. }\end{array}$ & $\mathrm{C} 8$ \\
\hline $\begin{array}{l}\text { 9. Asks for suggestion, direction, possible ways of } \\
\text { action. }\end{array}$ & C9 \\
\hline \multicolumn{2}{|c|}{ D. Social-emotional area: Negative reactions } \\
\hline $\begin{array}{l}\text { 10. Disagrees, shows passive rejection, formality, } \\
\text { withholds resources. }\end{array}$ & D10 \\
\hline $\begin{array}{l}\text { 11. Shows tension increase, asks for help, } \\
\text { withdraws out of field. }\end{array}$ & D11 \\
\hline $\begin{array}{l}\text { 12. Shows antagonism, deflates other's status, } \\
\text { defends or asserts self. }\end{array}$ & D12 \\
\hline
\end{tabular}

The category list (Table 2) is based on Bales' research. His categories were applied to four main areas, with each area divided into three subareas. Areas A and D represent opposing social-emotional areas, while areas $\mathrm{B}$ and $\mathrm{C}$ represent complementary task areas related to problem solving. The abbreviations for Bales' categories are depicted as a combination of the letter denoting the main area and the number of the subarea. These abbreviations are used to categorize each speech act and meaning construction element. The dynamic process of transforming meaning constructions and speech acts can be visualized using three-dimensional graphs, programmed in MMIE as shown in Figures 4 and 5.

\section{Case Study}

In this section, the effectiveness of the narrative social work model, discussed above, is demonstrated through a case study of $Y$, who was unable to generate his own story in the context of the strong downward force from the HIV/AIDS discourse. Moreover, the transformative process in which systematized intervention skills were applied to generate a differentiation force that enabled the construction of his unique story is discussed. This case was previously presented in an article published in the Japanese Journal of AIDS Research in 2010 [15]. Some of the transcripts included in the previous article have been re-translated in a natural English conversational style.

\subsection{Treatment Background}

$\mathrm{Y}$ is an HIV-infected male in his 30s. The cause of the infection was unprotected homosexual intercourse. He was admitted as an intensive care patient for pneumocystis pneumonia (PCP). His CD4, a T cell subtype, was 10, and his HIV-RNA, which is the part of HIV capable of creating other copies of the virus, was $1.0 \times 10^{5}$. He also had esophageal candidiasis. While still in the intensive ward, he was informed, for the first time, that he was HIV positive. A few days later, he was transferred to a standard ward to start Highly Active Anti-Retroviral Therapy (HAART). However, $Y$ repeatedly refused this treatment. Finally, the doctor gave up trying to persuade $\mathrm{Y}$ to undergo this treatment, and sanctioned his discharge without prescribing HAART.

\subsection{Y's Complaint}

Y complained that other people would never accept him, as he was HIV positive. Moreover, Y continued to refuse the medication protocol, and this refusal can and should be seen as the composition of a particular self-created context which generated the life of living with HIV/AIDS as being meaningless and without any hope. Conversely, he told the social worker that he wanted to reduce his physical pain and his difficulties with social relationships for the life remaining to him.

\subsection{Assessment and Intervention Plan}

The social worker assessed Y's complaints as a 
composition of the deviance amplifying process between his story, constructed in the context of problematic relationships with others, and the dominant HIV/AIDS discourse. Consequently, the social worker planned to activate a force of differentiation in transactions with others to construct $Y$ 's beneficial story by being able overcome the inhibitive force of HIV/AIDS discourse.

\subsection{Intervention Process}

To increase the differentiation force in Y's story, the following six steps were implemented. The categories of the social worker's messages were identified and marked at the end of the social worker's messages according to the information presented in Table 1. Each of the social worker's messages was indicated with the question abbreviations shown in Table 1 to distinguish between the main and secondary purposes. The main purpose was denoted with a forward slash [/], and secondary purposes were denoted with backward slashes. The mutual transformative process entailing the intervention message and the generation of difference in the client's problematic episode were clarified.

\subsubsection{Acquisition of New Self-definition as an Active Problem Solver}

To construct Y's position as a problem solver, the social worker positively reframed Y's complaints as a desired intention of trying to manage his life during the time he had left, and $\mathrm{Y}$ agreed to this. Here, a new horizon (positive life-script) emerged with $\mathrm{Y}$ as a problem solver.

\subsubsection{Acquiring a New Self-definition and Re-examining the Client's Life World}

To generate the force of a differentiation force in the vertical feedback loop, the social worker planned to encourage $\mathrm{Y}$ to reflect on the different meanings of his refusal to undergo treatment in the context of managing his remaining life.

1SW: I wonder if your refusal might have an important meaning for you... What benefit might you get now by refusing your medication? $(\mathrm{CCb} 4 / \mathrm{CCb} 2, \mathrm{CCb} 3)$

The social worker's main purpose here was to reflect on the meaning of his refusal as a problem-solving activity in the context of the client's life-script as a problem solver. Therefore, this was categorized as $\mathrm{CCb} 4$. In raising this question, the social worker was potentially encouraging $\mathrm{Y}$ to actively reflect on the positive meaning of his refusal in the context of an episode, and of a relationship level, as shown in Figure 2 (CCb2, CCb3).

2Y: ...Benefits?.....what?....I can't imagine any benefits.

3SW: OK...So...Well...in that case, are there any outcomes in which you could stop worrying about something by refusing your HAART medication? (CCb2/ CDd)

In $2 \mathrm{Y}$, although $\mathrm{Y}$ could not describe the beneficial episode, $\mathrm{Y}$ started to reflect on the positive meaning of his refusal. Therefore, the social worker's main purpose here was to encourage $\mathrm{Y}$ to describe some of the good outcomes in his life situation elicited by his refusal; for example, he could stop worrying about his remaining life, and so on. (CCb2). This message was also intended to identify one episode that he could manage (CDd: life event).

4Y: Now that I think about it, I'm able to let go of my feelings of anxiety.

5SW: That's very interesting. You are trying to reduce feeling anxious through your refusal, right? (PR, CCb4/ CCb6)

In his message above (4Y), $\mathrm{Y}$ was able to elicit the resolution episode that he had previously excluded. Consequently, the social worker's main purpose $(5 \mathrm{SW})$ was to reinforce his position as a problem solver ( $\mathrm{PR}, \mathrm{CCb} 4)$. The social worker was also potentially encouraging $\mathrm{Y}$ to reflect on the meaning construction of the episode of his anxiety by identifying the elements of the sequence. This was, therefore, categorized as CCb6 (upward mobility).

6Y: That might be so.

In $6 \mathrm{Y}, \mathrm{Y}$ was able to construct the positive meaning of his refusal as a resolution activity to curb his anxiety from a position as a problem solver. Subsequently, to reinforce his position as a problem solver, his anxious episodes were selected as a target episode for change. That is, downward mobility from the level of life-script to the level of the episode in Figure 2 was used to reconstruct the meaning construction of his anxious episodes. This kind of questioning was categorized as CCb6 (downward mobility).

\subsubsection{Tracking the Transactional Sequence of Y's Loneliness Situation}

To activate downward mobility, the social worker planned to encourage $\mathrm{Y}$ to describe the specific sequence of an episode entailing an anxiety arousing process in the upper level context of Y's life-script as a problem solver.

7SW: OK. I see... if you don't mind...could you tell me about the anxiety that you are trying to prevent from increasing now? (CCb6/ CDd)

In 7SW, the social worker's main purpose was to help $Y$ to describe the anxious episode that he was trying to control (CCb6). This message was also potentially intended to clarify the elements that comprised his anxious episode. Therefore, this was categorized as CDd (elements of life event).

8Y: Well, I could not have deep relationships with my previous partners. Moreover, I am HIV positive now. Nobody wants to have an intimate relationship with me. Also, my HIV status would not allow me to have sexual relationships with others. The more I think I have no cure for the body, the more I can stop worrying about my life without any sexual relationship, which is so lonely.

9SW: This sounds very impressive to me. You are trying to stop worrying about your future life without an intimate partner by your refusal, right?...Honestly, I'm not clear on how you think so hard about your future life...If you don't mind, could you tell me in more detail about it? (PR, CDd/ CDd) 
In $8 \mathrm{Y}, \mathrm{Y}$ described his anxious episode as a target for change. Subsequently, the social worker's main purpose in 9SW was to enforce downward mobility and to focus on his competence to stop worrying about his future life (PR). At the same time, the social worker attempted to encourage $Y$ to describe the episode entailing anxiety in the context of problem solving (CDd; life event). Moreover, the social worker also intended to ask $\mathrm{Y}$ to describe the concrete elements of the episode (CDd; behaviors).

10Y: Even if I were to fall in love with an HIV negative person who does not know about my condition, once I tell him "I am HIV positive (Y-1)", I'm sure that he will reject me.

11SW: You really imagine that if you told your future partner about your HIV status, you would be rejected by this future partner?...(pause)...So now, I would like to ask you, what do you imagine your future partner would say to you when you told him about your HIV status? (TCa/ CCa2)

In $10 \mathrm{Y}, \mathrm{Y}$ was able to identify one of the elements of the episode entailing anxiety. The social worker's main purpose in $11 \mathrm{SW}$ was to clarify the sequential elements of the target episode. Therefore, the social worker attempted to encourage $\mathrm{Y}$ to describe the behavior selection relating to his imagined future partner as a response to Y's message (TCa). The social worker also latently encouraged $\mathrm{Y}$ to explain the meaning construction of his imagined future partner's reaction to his notification ( $\mathrm{CCa} 2)$.

12Y: His face will become critical and he will say angrily to me, "Why didn't you tell me this at the beginning? (O-2)"

13SW: What would you think of this response? (CCa2/ CCa1).

In $12 \mathrm{Y}, \mathrm{Y}$ described his imagined future partner's response (O-2). Consequently, the social worker's main purpose in 13SW was to help $\mathrm{Y}$ to describe the meaning construction of his imagined future partner's message (Y-3). This was categorized as $\mathrm{CCa} 2$. Moreover, the social worker was potentially asking $\mathrm{Y}$ to imagine his response $(\mathrm{Y}-4)$ to his imagined future partner's message (O-2) to which he attributed a specific meaning $(\mathrm{CCa} 1)$.

14Y: If I were him, I would absolutely choose refusal. The fact that anyone would react this way is certain. I think his anger and criticism would be justified (Y-3). Therefore, I would not be able to say anything to him in reply (Y-4). Our relationship would be over. I could not endure that. I don't want to think about it anymore.

In the sequence from $10 \mathrm{Y}$ to $14 \mathrm{Y}, \mathrm{Y}$ clearly described the imagined elements (Y-1, O-2, Y-3, Y-4) of an anxiety-inducing episode associated with notifying an HIV negative person. These elements, described by Y, imply that $\mathrm{Y}$ was able to distinguish this episode from other episodes, as the most difficult one to deal with. Therefore, the social worker planned to encourage $\mathrm{Y}$ to reflect on the excluded elements of the episode to activate the differentiation force.

\subsubsection{Differentiation of Episodes}

Previously, the social worker focused on the category of
Y's imagined future partner as being HIV negative. Thus, an HIV positive person with whom Y would fall in love in the future was excluded.

15SW: I see. Well...I guess... what comes to my mind now... I wonder... Can you imagine what would happen with a future partner, whom you informed about your HIV status, who might also turn out to be HIV positive? (CDd/ $\mathrm{CDd}, \mathrm{CCa} 2)$

The social worker's main purpose in $15 \mathrm{SW}$ was to help $\mathrm{Y}$ to imagine the anxiety-inducing notification episode with someone who was HIV positive. This question was also intended to elicit the sanctioned meaning construction of the episode (CDd: life event). Moreover it was implicitly intended to differentiate the imagined other's response to his notification (CDd: behaviors) and his meaning construction of the other's response to him (CCa2).

16Y: Well...I guess...uh, at least...he might not refuse me because I am HIV positive....

17SW: How do you imagine his response to you? (CDd/ $\mathrm{CCa} 2, \mathrm{CCa} 1)$

In $16 \mathrm{Y}, \mathrm{Y}$ imagined that he might be accepted by a future partner when he revealed his HIV status to his partner. Then, the social worker's main purpose in $17 \mathrm{SW}$ was to clarify the element in the transaction to form the structure to activate a force of differentiation in relation to Y's notification message (CDd: behavior). Potentially, the social worker would ask $\mathrm{Y}$ to describe the meaning of a future partner's response (CCa2) and Y's response to a future partner's response (CCa1).

18Y: I'm not sure...but I would probably feel less fear of rejection.

19SW: What kind of subsequent response would you choose if you wanted to mitigate your anxiety regarding the other's message? (CCa1/ TCa)

Although Y could not clearly describe a future partner's message in $18 \mathrm{Y}$, he could vaguely imagine the meaning construction of the episode that he would feel a reduction in the fear of rejection when he received the message from a future partner who was HIV positive. Consequently, the social worker's main purpose in 19SW was to ask Y to visualize his response after receiving a message that would enable him to reduce his anxiety much further (CCa1). Moreover, the social worker intended to ask $\mathrm{Y}$ to imagine the result of the transaction of reducing his fear of rejection (TCa).

\section{Y: I am not sure...}

In 20Y, Y could not clearly imagine his response. Therefore, the social worker changed the plan to one of differentiating the elements of this sequence to emerge as another episode with another person who could create an episode entailing the reduction of his fear of rejection.

\subsubsection{Intervention to Expand The Scope of the Relationship} to Construct Y's Life-script as an Acceptable Person 
As a next step, the social worker planned to help Y to reflect on the episode in relation to a wide range of other people. Thus, not only was an imagined future partner who was HIV negative considered, but also persons in his everyday life, including his friends, who were HIV free. Thus, the social worker planned to expand the differentiation force from the episode level to the relationship level.

21SW: Well, can you imagine being an acceptable person, who is HIV free, yet, who is able to generate a notification episode during which you reduce your fear of rejection? $(\mathrm{CCb} 3 / \mathrm{TCa})$

The social worker's main purpose in $21 \mathrm{SW}$ was to help $\mathrm{Y}$ to reflect on a relational meaning in the context of a notification episode during which he could reduce his fear of rejection (CCb3). Thus, upward mobility was used. The social worker potentially helped $\mathrm{Y}$ to clarify the transactional process of the notification episode between $\mathrm{Y}$ and a person who would accept him (TCa).

22Y: ...Is there such a person... who could have an acceptable response...? Umm...oh, I just remembered, I know one person, Z, who always accepts me as I am.

23SW: That sounds great! Could you tell me what you would say to $\mathrm{Z}$ ? (TCa/ CCa1, CCa2)

In $22 \mathrm{Y}, \mathrm{Y}$ finally discovered a person, $\mathrm{Z}$, who could accept him when notified of his HIV status. This meant that the differentiation force was beginning to activate in the vertical feedback loop. The social worker's main purpose in $23 \mathrm{SW}$ was to encourage $\mathrm{Y}$ to imagine a concrete transaction with his friend, $\mathrm{Z}$, who was an acceptable person (TCa). This meant that the activation of the differentiation force in the vertical feedback loop was needed to expand the horizontal feedback loop. In other words, if Y could implement a strategy of informing $Z$, and if this was successful, the differentiation force would be activated in the vertical feedback loop as well as in the horizontal feedback loop. Clarification of a sequence of behaviors and meaning constructions in this episode would potentially be chosen by the social worker $(\mathrm{CCa} 1, \mathrm{CCa} 2)$. The clarifications of these elements contributed to an actual implementation plan for informing an acceptable friend of his status.

24Y: To be honest, I am thinking about how to talk to him about my HIV status.

Y's description represented the beginning of the creation of a new relationship with his friend, $Z$, as a person who lives with HIV. Therefore, to reinforce Y's practical force, the social worker planned to help $\mathrm{Y}$ to develop an implementation plan during the next step.

\subsubsection{Clarification of the Implementation Plan Relating to Y's Friend, Z}

In this phase, the social worker encouraged $\mathrm{Y}$ to describe the concrete elements of meaning constructions and behavior selections of the implementation plan with his friend, $\mathrm{Z}$.

25SW: That's really very interesting. You are already planning to do it! Could you tell me how you might start to tell him about it? (CDd/ TCa)

After the social worker complimented $\mathrm{Y}$ on being a problem solver in $25 \mathrm{SW}$, $\mathrm{Y}$ was encouraged to describe an initial message consisting of an HIV notification episode with $\mathrm{Z}$, in which Y's anxiety was not aroused (CDd: behavior). The social worker would potentially ask $\mathrm{Y}$ to imagine a possible response by $\mathrm{Z}$ to $\mathrm{Y}$ 's message (TCa).

26Y: Well, I will tell him simply and not seriously, "I am HIV positive (Y-1)" in the natural course of our conversation.

27SW: What kind of reaction do you suppose he will have? ( $\mathrm{TCa} / \mathrm{CCa} 2)$

In $26 \mathrm{Y}$, $\mathrm{Y}$ was able to imagine and explain how to initiate the episode with $Z$. The social worker's main purpose in $27 \mathrm{SW}$ was to ask $\mathrm{Y}$ to imagine his friend $\mathrm{Z}$ 's concrete response (TCa). Y would potentially be asked to imagine the meaning construction of the response that he would receive from $\mathrm{Z}(\mathrm{CCa} 2)$.

28Y: I can imagine that his facial expression would not change when he heard of my HIV status, and he would ask me in his natural way, "Well, in fact, how serious is your condition? (O-2)"

29SW: How would you feel getting such a response? (CCa2/ CCa1)

In 28Y, Y was expecting the response of his friend $\mathrm{Z}$. Subsequently, the social worker's main purpose in $29 \mathrm{SW}$ was to ask Y about the meaning construction of his friend Z's response (CCa2). Y would potentially be asked to imagine what kind of message he would choose for responding to his friend Z (CCa1).

30Y: I would understand it as a non-judgmental expression, so I would feel accepted by him (Y-3).

31SW: How would you then respond to him in this case? (CCa1/ CCb5)

In $30 \mathrm{Y}, \mathrm{Y}$ described the concrete response of his friend, $\mathrm{Z}$. Thus, the social worker's main purpose in $31 \mathrm{SW}$ was to encourage $\mathrm{Y}$ to imagine his response to $\mathrm{Z}$ (CCa1). The social worker intended to ask $\mathrm{Y}$ whether or not he could implement it the near future $(\mathrm{CCb} 5)$.

32Y: I may answer, "It's no problem (Y-4). I'm fine. No need to worry," and continue to talk as usual.

33SW: Can you practice this implementation with $\mathrm{Z}$ in the near future? (CCb5/ TCa)

In 32Y, Y explained his response, which succeeded in reducing his anxiety regarding rejection. Subsequently, the social worker's main purpose in $33 \mathrm{SW}$ was to activate upward mobility to reinforce Y's life-script as a problem solver through the implementation in the horizontal feedback loop (CCb5). In addition, the social worker potentially helped $\mathrm{Y}$ to enforce a practical force to achieve this in the horizontal feedback loop (TCa)

34Y: Yes. I will do it when I feel the time is right when I meet him next week.

In 34Y, Y could describe his implementation plan more concretely. 
Y successfully implemented this plan with his friend, $\mathrm{Z}$. This implementation operated as an activation of a differentiation force in Y's horizontal feedback loop. Next, to let this differentiation force linkage activate a force of differentiation in the vertical feedback loop, the social worker encouraged $\mathrm{Y}$ to describe and reflect on the concrete elements of his implementation with $\mathrm{Z}$ using circular questions. $Y$ could consequently redefine himself as an acceptable person, and as a problem solver who could reduce his own anxiety in the context of this episode. After this reflection phase, the differentiation force in his horizontal feedback loop was further activated. Y tried to share his concern about having HAART with other HIV positive persons, who were already undergoing this treatment, but was not satisfied with a conversation with an HIV positive person. Through this experience, $\mathrm{Y}$ started to find that the medical condition of being HIV positive was not the most important thing in understanding each other. This transformation of the definition of the relationship with HIV operated as a form of power in the deconstruction of the dichotomy of HIV positive and HIV negative individuals in his vertical feedback loop. In other words, $\mathrm{Y}$ was able to gain an upper position that enabled him to construct his reality against the HIV/AIDS discourse.

Finally, Y decided to take HAART, and to find a new sexual partner. Through his involvement in HAART, its meaning was transformed into resource material that enabled him to maintain his relationships with others. He did not experience any severe side effects. Currently, his HIV condition is well managed, and he still has his career and reportedly lives a fulfilling life.

\subsection{Measurement}

In this section, the measurement methods are discussed in light of Y's case. The effectiveness of this transformation process can be explained in terms of the activation of the differentiation force between pre- and post-intervention phases. In this case, the elements of the notification episode in which Y's anxiety about being rejected based on having HIV/AIDS increased were data of the measurement in the pre-intervention phase as well as the elements of transformation The elements of this episode were Y's descriptions (Y-1, O-2, Y-3, and Y-4) provided during the third step of the intervention process, as indicated in Table 3. These elements were categorized using Bales' categories. The data were categorized by more than two researchers well versed in this categorization method. Y-1 was conveyed in a serious way to an imagined future partner, inducing a high level of tension. Therefore, D11 in the social-emotional area was selected as the category for Y-1. The imagined future partner's message (O-2) was conveyed to $\mathrm{Y}$ in a negative emotional way, both verbally and nonverbally. Therefore, D12 was selected for the social-emotional area.
Table 3. Pre-intervention data

\begin{tabular}{|c|l|c|}
\hline Subject & The element of sequence & Categorization \\
\hline $\mathrm{Y} 1$ & $\begin{array}{l}\text { (Seriously) I am HIV } \\
\text { positive. }\end{array}$ & $\mathrm{D} 11 \mathrm{~s}$ \\
$\mathrm{O} 2$ & $\begin{array}{l}\text { (Angrily) Why didn't you } \\
\text { tell it to me from the } \\
\text { start ? }\end{array}$ & $\mathrm{D} 12 \mathrm{~s}$ \\
\hline $\mathrm{Y} 3$ & $\begin{array}{l}\text { His message means } \\
\text { rejection to me. }\end{array}$ \\
\hline $\mathrm{Y} 4$ & $\begin{array}{l}\text { (I can't say anything to } \\
\text { him in reply) }\end{array}$ \\
\hline
\end{tabular}

Notes: " $\mathrm{s}$ " indicates a speech act and " $\mathrm{m}$ " indicates meaning construction

As the negative meaning of $\mathrm{O}-2$ was anticipated by $\mathrm{Y}$, it was categorized as D12 (Y-3) and Y responded emotionally to the other person (Y-4). Therefore, Y-4 was also categorized as D12. The categories of each element are indicated in the last column of Table 3. All elements were categorized in section D of Bales' categories. This indicated that the differentiation force was reduced.

Through Y's implementation with his friend $Z$, the other's message (O-2) as a response to Y's notification message and the sequential elements were really actualized. New elements of the notification episode are identified as data in the post-intervention phase and a result of Y's implementation of his plan with his friend, Z. These elements and categorizations are shown in Table 4. These elements are categorized in sections A and B of Bales' categories.

Table 4. Post-intervention data

\begin{tabular}{|c|c|c|}
\hline Subject & $\begin{array}{c}\text { The element of } \\
\text { sequence }\end{array}$ & Categorization \\
\hline Y1 & $\begin{array}{l}\text { (Not seriously) I am HIV } \\
\text { positive. }\end{array}$ & B5s \\
\hline $\mathrm{O} 2$ & $\begin{array}{l}\text { (Not change his facial } \\
\text { expression) } \\
\text { Well, in fact, how serious } \\
\text { is your condition? }\end{array}$ & A $3 \mathrm{~s}$ \\
\hline Y3 & $\begin{array}{l}\text { His message means the } \\
\text { acceptance of me. }\end{array}$ & $\mathrm{A} 3 \mathrm{~m}$ \\
\hline Y4 & It's no problem. & B6s \\
\hline
\end{tabular}

Notes: "s" indicates a speech act and " $\mathrm{m}$ " indicates meaning construction

The categorized elements in Tables 3 and 4 were plotted in three-dimensional graphs, depicted in Figures 4 and 5. The procedure for plotting the graphs was as follows. First, Y-1 (D11s) was inserted on the X-axis and O-2 (D12s) was inserted on the $\mathrm{Y}$-axis. The crossing point is shown as (1) in Figure 4. Next, O-2 (D12s) was inserted on X-axis and Y-3 (D12m) was also inserted on the $\mathrm{Y}$-axis. The crossing point is shown as (2) in Figure 4. The arrows indicated the direction of the differentiation force. The data in Table 4 were plotted in a three-dimensional graph using the same procedure described above as depicted in Figure 5. Figures 4 and 5 were created using MMIE.

The dynamics of the sequence, shown in Figure 4, indicate a reduction of the differentiation force between points (1) and (3). Continued plotting of the same crossing point indicates that both subjects continued to choose similar 
ranges of meaning construction and behavior selection of Bales' categories. This relates to generating a deviation force.

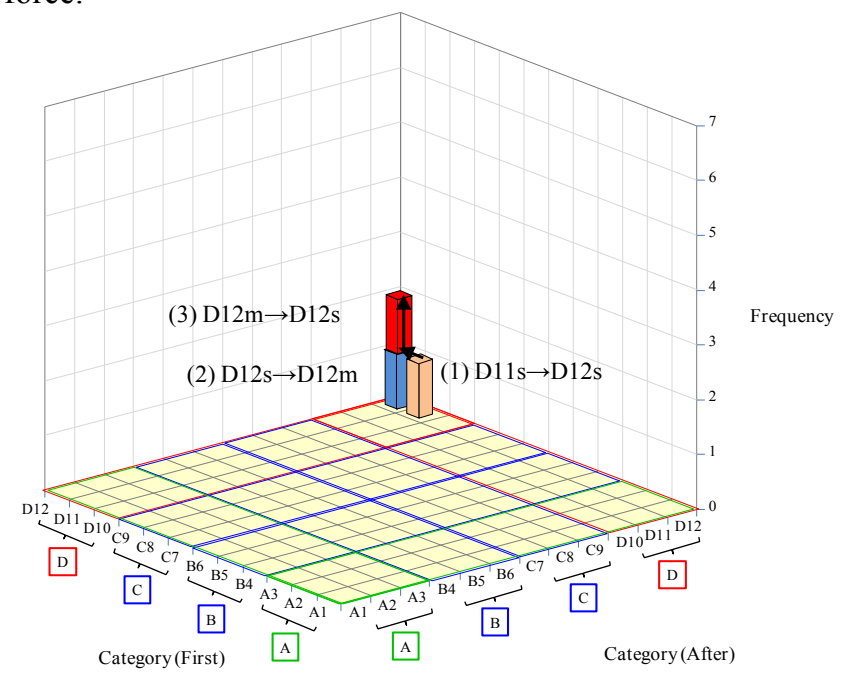

Figure 4. Dynamics of pre-intervention data

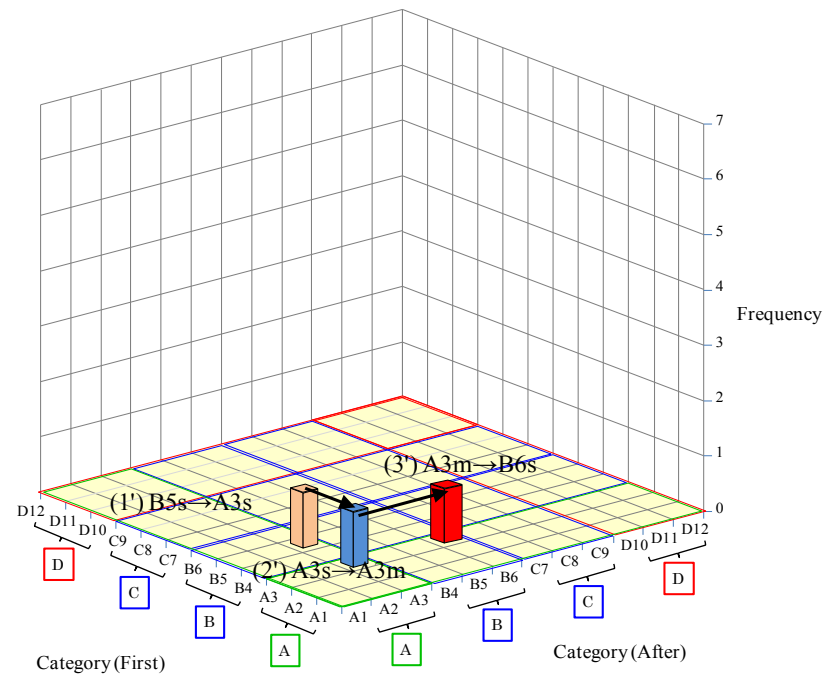

Figure 5. Dynamics of post-intervention data

In contrast to Figure 4, Figure 5 indicates the multiple crossing points and the directions of different sections between crossing points from (1') to (3'). That is, the notification episode in the post-intervention phase indicated the activation of a force of differentiation compared with the notification episode in the pre-intervention phase.

\section{Discussion}

This article presented a theoretical framework with which to construct a person's reality in a co-generative dynamic between the vertical and the horizontal feedback loops. A story as a multilayered meaning structure is constructed by activities that give meaning to others' behaviors in the experiential world. Conversely, the constructed story operates as a pre-conditional force to generate the activities in the life world. The force of the institutionalized discourse operates to continue the present rules of the person's reality construction as a truth. That is, this is a more sophisticated framework than a linear explanation of a generation of the world from the restrictive force of the dominant story.

A new intervention methodology to transform the client's suffering story based on this theoretical framework was systematized. This methodology can explain the transformation process of activating a differentiation force that can construct a beneficial story. This is accomplished by converting the problematic story into the elements of the sequence, identifying the target element for the transformation, and reflecting on the elements using the intervention skills. Then, a client's beneficial story constructed in the therapeutic process has a contextual transformative force that can activate an implementation force of solution activities in the client's life situation. That is, the activating process of the differentiation force involved in a client's beneficial story construction was indicated through the concrete intervention process of Y's case, according to the transformation procedure. This intervention methodology is more explainable than a narrative approach.

Furthermore, systematized applications of the intervention skills and their tactical use have been demonstrated by sorting these messages into primary and secondary purposes through the case study, as well as by categorizing each of the social worker's messages. The categorization of the intervention skills involved in multiple meanings of a therapist's message and the tactical use of the intervention skills has not been discussed so far. The tactical use of the intervention skills is also indicated as a refined usage of circular questions. This account of the systematized application of intervention skills could help practitioners discuss the effective use of these intervention skills rather than just externalizing the force of the dominant story.

The method used to measure the transformation process presented in this article is the first attempt to engage with the social constructionist approach. The transformation process can be demonstrated by identifying the elements of the sequence that generates the client's story as a level of measurement. In addition, it can be visualized by plotting each element categorized according to Bales' categories on our unique three-dimensional graph. This method of visualizing the activation of the differentiation force by comparing pre- and post-intervention data is unique and more creative than other qualitative measurement methods in the social work field.

In addition, the evidence for the effectiveness of this approach for HIV/AIDS clients is supported through the results from the case study of Y. Thus far, the great variety of adaptation problems of HIV/AIDS clients has been explained deductively as problems caused by social discrimination. It should be recognized, however, that these sorts of explanations, are, in fact, a form of "discourse 
reductionism". The model suggested here, aims to avoid reductionism in its understanding and analysis of the HIV/AIDS client's social adaptation problems, which are rather seen as a composite construction generated in and from the mutual dialectical process among discourses, stories, and the transactions of everyday social interaction. Therefore, our model is innovative and unique in this area of therapeutic approaches for the HIV/AIDS client, offering a natural problem resolution method, which is effective, precisely because it is non-reductionist.

Finally, this model is still in progress, and there are some aspects relating to intervention skills and measurement methods that need further discussion. For example, theorization regarding sorting the therapist's messages into primary and secondary purposes is not yet sufficient. Therefore, the recommended formulation of intervention skills will be constructed through multiple case studies. In addition, we need further discussion of the methodology to identify those elements that can be measured, and the reliability and validity of this measurement method must be tested.

\section{Conclusions}

This article presents an innovative framework of a narrative social work model, incorporating basic theory, clinical theory, systematized intervention skills, and measurement methods. The effectiveness of the model was demonstrated with one case study. This narrative social work model may develop into an effective model that could improve the construction of HIV/AIDS clients' life worlds. The specific application of intervention skills and the measurement methodology require further improvements.

\section{Acknowledgements}

This work was supported by JSPS KAKENHI Grant Number 24530712.

\section{REFERENCES}

[1] M. Foucault. Truth and power. In C. Gordon (Ed.). Power/ Knowledge: Selected Interviews and Other Writings, 1972-1977, Pantheon, New York, 109-133, 1980.

[2] G. Bateson. Steps to an Ecology of Mind. Ballantine, New York, 1972.
[3] M. White, D. Epston. Narrative Means to Therapeutic Ends. Norton, New York, 1990.

[4] V. E. Cronen, W. B. Pearce. Toward an explanation of how the Milan Method works: An invitation to a systemic epistemology and the evolution of family systems. In D. Campbell and R. Draper (Eds.). Applications of Systemic Family Therapy: The Milan Approach, Grune and Stratton, New York, 69-84, 1985.

[5] K. Tomm. Circular interviewing: a multifaceted clinical tool. In D. Campbell \& R. Draper (Eds.). Applications of Systemic Family Therapy: the Milan Approach. Grune and Stratton, New York, 33-45, 1985.

[6] K. Tomm. Interventive interviewing: part 1. Strategizing as a fourth guidelines for the therapist. Family Process Vol. 26, 3-13, 1987 .

[7] K. Tomm. Interventive interviewing: part 2. Reflexive questioning as a means to enable self-healing. Family Process, Vol. 26, 167-183, 1987.

[8] K. Tomm. Interventive Interviewing: Part 3. Intending to ask lineal, circular, strategic or reflexive questions? Family Process, Vol. 27, 1-15, 1988.

[9] P. De Jong, I. K. Berg. Interviewing for Solutions (2nd edition), Brooks/ Cole, California, 2002.

[10] G. R. Weeks, L. L'Abate. Paradoxical Psychotherapy: Theory and Practice with Individuals Couples and Families. Brunner/Mazel, Inc., New York, 1982.

[11] K. Kamo, K. Maeda. Categorization of intervention skills (unpublished paper), 2014

[12] R. F. Bales. Interaction Process Analysis: a Method for the Study of Small Groups. Addison-Wesley Press, Inc, Cambridge, Mass, 1950.

[13] K, Kamo, Y. Oshita. Evidence based social work 2 (in Japanese), Studies on Social Work, Vol. 34, No. 1, 39-46, 2008.

[14] Y. Oshita, K. Kamo, Measuring the effectiveness of the short-term reconstructing of meaningful life worlds (SRM) (in Japanese), The Japanese Journal of Family Psychology, Vol. 27, No. 1, 1-15, 2013.

[15] Y. Oshita, Clinical social work practice with HIV/AIDS patients, The Journal of AIDS Research, Vol. 12, No. 2, 119-123, 2010.

[16] C. C. Poindexter. The human rights framework applied to HIV services and policy. In C. C. Poindexter (Ed.). Handbook of HIV and Social Work: Principles, Practice, and Populations, John Wiley \& Sons Inc., New Jersey, 59-73, 2010. 